\title{
LA VANGUARDIA EN ANTOLOGIAS. PAPEL DE HUIDOBRO
}

La vanguardia en las letras hispánicas no ha tenido en las antologías la suerte que se merece. Esto se debe ante todo a que los compiladores han respondido a instancias de grupo, tendencias $\mathrm{u}$ otros exclusivimos, cuando no a limitaciones de orden nacional. En este sentido -el de representar, por ejemplo, la poesía de un país o de un determinado período-, los logros han sido más efectivos, y en contados casos, de validez imprescindible. Ejemplos: la Exposición de la actual poesía argentina: 1922-1927 (Buenos Aires: Minerva, 1927), de Pedro Juan Vignale y César Tiempo, o Poesía española. Contemporáneos (Madrid, 1932), de Gerardo Diego. Guillermo de Torre se ha quejado de que en esta última, como en la Antología de poetas españoles contemporáneos, publicada al año siguiente en Santiago de Chile por José María Souvirón, y en la de Juan J. Domenchina, Antología de la poesía española contemporánea: 1900-1936 (México, 1941), se haya excluido a notorios representantes del ultraísmo ${ }^{1}$. Lo mismo puede decirse de la antología denominada Laurel, aparecida en México el mismo año de 1941 y compilada por poetas de la talla de Emilio Prados, Xavier Villaurrutia, Juan Gil Albert y Octavio Paz. Habrá que llegar a nuestros días para hallar una antología continental y abarcadora de un específico movimiento de vanguardia: la Antología de la poesía surrealista latinoamericana, de Stefan Baciu (México: Joaquín Mortiz, 1974). No existe, pues, una antología del ultraísmo español y argentino o del creacionismo chileno y de la América hispánica, si bien hay buenos estudios críticos y documentales sobre cada una de estas expresiones vanguardistas, como el de Gloria Videla para el ultraísmo, el volumen sobre Huidobro compilado por René de Costa, los de Schneider y Affonso Avila sobre el estridentismo mexicano y «o modernismo» brasileño, respectivamente.

${ }^{1}$ G. de Torre, Ultraismo, existencialismo y objetivismo en literatura (Madrid: Guadarrama, 1968), pp. 16-21. 
La más valiosa exposición de conjunto de la poesía hispánica (de España y de América) sigue siendo la ya clásica Antología de la poesía española e hispanoamericana, de Federico de Onís (Madrid: Revista de Filología Española, 1934); pero es obvio que este corpus resulta hoy deficiente no sólo en el aspecto crítico-documental, sino también en lo que concierne a la selección misma de los autores y los textos. Desgraciadamente, el autor no hizo el debido ajuste up-to-date en una segunda edición de Las Americas Publishing de Nueva York.

Por lo que toca a la América de habla española, abundan las antologías nacionales y hay no pocas que se titulan Poetas de Hispanoamérica (Solar Correa, Santiago de Chile, 1926), Florilegio del parnaso americano (De Vittis, Barcelona: Maucci, 1927), Poetas jóvenes de América (A. Guillén, Madrid, 1930), Antología de poetas hispanoamericanos (F. Monterde, México, 1931) y la más lujosa y vulnerable de todas, la Antología de la poesía hispanoamericana, de Julio Caillet-Bois (Madrid: Aguilar, 1965). No es mi propósito seguir con estas enumeraciones, pero debo salvar de una crítica negativa a la Antología de la poesía hispanoamericana contemporánea: 1914-1970, de José Olivio Jiménez (Madrid: Alianza Editorial, 1971), y a la Antología de la poesía viva latinoamericana, de Aldo Pellegrini (Barcelona: Seix Barral, 1966), dos exposiciones necesarias de la producción poética hispanoamericana del período que enmarca la vanguardia. En la de Jiménez hay el propósito de exposición objetiva y de criterio ecléctico de quien está tratando con un material ya establecido. En la de Pellegrini es obvio el deseo de ser la presentación de un tipo de poesía con el que comulga el compilador, comprometido él mismo con el surrealismo. $\mathrm{Y}$ así viene a ser, por ahora, como el final de un ciclo que instaura una línea de textos de la vanguardia, que se inicia con la primera y muy recomendable selección sobre La nueva poesía de América, de Rafael Heliodoro Valle (México, 1924), y sigue, no sé si con igual predicamento, aunque sea más difundida y utilizada, con la que voy a ocuparme: el Indice de la nueva poesía americana (Buenos Aires: Sociedad de Publicaciones El Inca, 1926), que firman Alberto Hidalgo, Vicente Huidobro y Jorge Luis Borges.

Desde luego no ha de ser casual que estos tres nombres aparezcan unidos al frente de una presentación de textos de la nueva poesía de la América hispánica; que represente, como dijeron Ortega y Gasset y Vicente Huidobro en Buenos Aires en 1916, la «nueva sensibilidad». No se trata de tres scholars que se unen para realizar una tarea más o menos assembly work, sino de tres líderes de tres manifestaciones fundamentales de la vanguardia poética. Si a ellos se hubieran juntado Maples Arce y Mariano Brull, hubiéramos contado con el quinteto per- 
fecto de nuestra poesía de avanzada. La ausencia de los países del Caribe en el Indice hace más lamentable la falta de un colaborador vanguardista de Cuba.

\section{¿CÓMO SE HIZO ESTE «INDICE» Y QUÉ REPRESENTA?}

A poco de ser publicado el Indice recibió reseñas dispares de Jean Cassou (La Revista de América, París, XIII, 1927, pp. 375-376) y Guillermo de Torre (Revista de Occidente, Madrid, XV, 1927, pp. 267273). Este último nos informa de que la compilación fue hecha por Alberto Hidalgo y no por los tres que firman las tres secciones consecutivas del prólogo ${ }^{2}$. O sea, que el Indice no sólo no lo es de toda la

${ }^{2}$ En carta de Hidalgo a Huidobro se confirma la información de G. de Torre. El original de dicha carta se conserva en el archivo de la familia Huidobro, en Santiago de Chile. La copia que reproducimos fue obsequiada a René de Costa por don Vicente García Huidobro Portales, hijo del poeta, a quien agradecemos el permiso de publicación. El texto completo de la carta de Hidalgo dice así:

Buenos Aires, 11 de enero de 1926.

Sr. Vicente Huidobro.

Santiago.

Distinguido compañero:

Una madrugada, en Madrid, creo que León Felipe nos presentó. Vd. no me recordará. Yo sí le recuerdo. Si no mediara esta circunstancia, igualmente le escribiría.

Florit le dirá a Vd. que estoy por publicar una antología de toda la poesía americana de vanguardia. Espero que este libro tendrá una resonancia intercontinental. Va a resultar una revelación para Europa. Tenemos poetas de izquierda tan buenos como los mejores de Francia.

Deseo que Vd. escriba un capítulo del prólogo. Por su obra personal primero, por los discípulos que ha hecho y luego por lo que significa dentro de la lírica española como solución de una época literaria: el rubenismo, que $\mathrm{Vd}$. echó por tierra; por todo eso, quiero que $\mathrm{Vd}$. escriba unas páginas del prólogo, que así tendría tres capítulos; los otros dos llevarían mi firma y la de Jorge Luis Borges, argentino. Pero hay otra razón también que me mueve a pedirle esto: que Chile es uno de los países que en América van a la cabeza del arte nuevo. Salen de ahí acaso los mejores poetas actuales. $V d$. debe decir unas palabras a la cabeza del libro. El espacio que quiera para decir lo que quiera. Pero que sea pronto. Mándeme su parte, certificada, a esta dirección: Ventura Bosch 6740 . De los poetas más importantes aparecerán 10 composiciones. Me faltan de Vd. 3 para enterar cifra. Mándeme "Ecuatorial», que es de donde quiero tomar unas que ya no me acuerdo de memoria. $O$ cosas inéditas, si le parece mejor. Pero mándeme siempre «Ecuatorial».

Le renuevo el apretón de manos de aquella noche en Madrid. 
poesía de América, como se verá, lo cual desmiente el título, sino que tampoco parece ser el desiderátum de los dos máximos promotores del vanguardismo de nuestra América. El hecho de que sea un índice y no una antología es también cuestión de importancia, porque denuncia la falta de planeación conjunta y estéticamente orgánica del volumen. Aunque el índice de autores se ordena por países, el corpus del libro lo está por orden alfabético, «con ausencia de toda clase de precisiones críticas y aun de datos biográficos y bibliográficos», como anota G. de Torre, de importancia para conocer a los autores incluidos y a situarlos debidamente. La cantidad de poetas seleccionados por cada país (16 para Argentina; 16 para Chile; 14 para Perú, y sólo 6 para México, 4 para Uruguay, 2 para Ecuador, 1 para Guatemala, 1 para Nicaragua y otros tantos para Colombia y Venezuela, pero nada para Bolivia, Paraguay y las repúblicas del Caribe, como ya notamos) podría hacer pensar en la intención pro domo sua de colaboradores participantes. Más bien me inclino a creer que la representación argentina se debió a que Hidalgo era amigo de Borges y de los poetas escogidos o porque el poeta del simplismo, si bien era peruano, había vivido desde joven en Buenos Aires. La unión de estos tres prologuistas se debe, pues, a razones no ya personales, sino de comunión poética. Este es punto que exige más investigación: alguna otra carta en archivo o declaraciones más precisas de los participantes. Huidobro no hace referencia, que yo sepa, a este Indice, y más parece ignorarlo en absoluto, así como no hay texto huidobriano que aluda a Borges, su amistad con él, su conocimiento en Buenos Aires o Madrid. Borges, por su parte, no ha prestado atención alguna a esta compilación de Hidalgo, ni la parte del prólogo que le corresponde se recoge en el volumen titulado Prólogos con un prólogo de prólogos, editado por Torres Aguiero en 1975. En su «An autobiographical essay», tan difundido con la edición inglesa (Bantam Books, de Dutton Press, 1970) de The Aleph and other stories, no hay mención de este libro ni de los otros dos prologuistas, y lo mismo ocurre en otros textos autobiográficos de Borges. El año 1926 figura en la cronología de María Esther Vázquez con "Otro libro que no reeditará: El tamaño de mi esperanza». En fin, conjeturamos que Borges, por haber abjurado de su «equivocación ultraísta» y por haber denunciado su «estética del prisma», como llamó a la época ultraica (ésta es también palabra suya), nada quiere saber del epónimo Indice, suponiendo que alguna intervención hubiese tenido en su preparación. $Y$ podemos pensar que en situación semajante se encuentra Huidobro, aunque sólo en cuanto a la participación directa como coautor del Indice, porque en lo que respecta 
a la poética misma allí representada, Huidobro sería su paradigma teórico-práctico ideal. Veamos esto.

Por supuesto que no vamos a discutir la originalidad de Huidobro, ni menos la prelación de su doctrina creacionista con respecto a Reverdy o al Ultra. Ni nos corresponde ahora ver si el creacionismo de Huidobro es una versión del ultraísmo o éste lo es del creacionismo. Más bien pensamos que hay una línea de ascenso y separación del referente hacia la imagen libre y la metáfora de lo disímil, que puede remontarse, qué se yo, a Góngora o a la poesía arábiga medieval, pero que los antecedentes más inmediatos están en Baudelaire, Mallarmé, Saint-Pol-Roux, el cubismo, Apollinaire, en una simultaneidad de búsquedas que polarizó en torno a revistas francesas como Elan, Sic, Littérature, Nord-Sud, y españolas como Grecia, Ultra, Cervantes y otras. Textos de Reverdy, Huidobro y Borges a menudo coinciden en tópicos esenciales de una poética que sustituye el principio mimético por el creacionista, o como se dice en el Cratilo de Platón, el principio de la fusei por el de la thesei. Huidobro pasó por Buenos Aires en 1916, donde expuso su doctrina creacionista y dejó «su libro» con un "Arte poética» que hacía del poema una sustitución de la naturaleza, un agregado o acrecentamiento de la misma. Fue a Madrid en 1916 (brevemente, de paso hacia París) y en 1918, año en que causó en la juventud de la tertulia de CansinosAsséns un verdadero impacto de renovación: el acontecimiento fundamental del año, como voceó el anfitrión de «El Colonial». Ese año publicó en Madrid cuatro de sus libros de más obvia voluntad vanguardista, en la línea cubista (Apollinaire, Reverdy, especialmente). Este último no tardó en disputarle la paternidad de la poética que ambos practicaban, en una entrevista que Enrique Gómez Carrillo difundió desde El Liberal de Madrid. Huidobro vuelve a la capital española en 1919 y 1920 y da a conocer poemas de su nueva estética en revistas ultraístas, como Grecia, Cervantes, etc. En cuanto a Borges, sabido es que no estaba en Buenos Aires en 1916, sino en Ginebra, leyendo a Carriego y probablemente practicando su alemán en textos de Schopenhauer, Heine, Der Golem de Meyrink, aburriéndose con Jean-Paul Richter o preparando una primera versión antológica de los poetas expresionistas, que poco después publicará en una revista ultra de España. Esto hasta 1919. Este año se lo ve pasear por Lugano, Sevilla y Mallorca, mientras Huidobro hace un rápido viaje a Chile y vuelve a París, pasando por Madrid, como vimos. Borges parece haber estado en Madrid parte de 1920 y los primeros meses de 1921, y no hay indicios de que se haya encontrado con Huidobro. En marzo de 1921 vuelve a Buenos Aires, y poco después de su salida de Madrid, Huidobro expone su doctrina creacionista en el 
Ateneo. Pero Cansinos-Asséns fue amigo de ambos y escribió sobre Huidobro y sobre Borges. De modo que si no se encontraron personalmente, Huidobro y Borges sabían por dónde cada uno andaba, y no sólo como viajeros del espacio, sino, y sobre todo, como buscadores de un nuevo modo de concebir el acto poético. De sobra sabemos cómo lo expuso Huidobro, pero no siempre se ha precisado bien cómo entendió Borges ese acto poético, que en sus momentos madrileños no fue muy diverso de cómo lo entendían Reverdy y Huidobro. Sólo voy a referirme a un texto bastante poco conocido, que se desenterró de una revista balear y se reprodujo en el número 291 de Insula, de Madrid, en febrero de 1971. Es un manifiesto ultra de 1920, y allí se hace la distinción entre una «estética de los espejos», pasiva, y «la estética activa de los primas». Esta última es la estética del ultra y su «volición es crear», se recalca. Esta afirmación concuerda con otro texto de 1920, aparecido en el número 31 de Grecia. Se titula «Al margen de la moderna lírica», y su doctrina esencial es la siguiente:

El ultraísmo es la expresión recién redimida del transformismo en literatura. Esa floración brusca de metáforas que en muchas obras creacionistas abruma a los profanos se justifica así plenamente y representa el esfuerzo del poeta para expresar la milenaria juventud de la vida que, como él, se devora, surge y renace en cada segundo... Esta premisa tan fecunda que considera las palabras no como puentes para las ideas, sino como fines en sí, halla en él su apoteosis.

O sea, en 1920 Borges era tan creacionista como Huidobro y Reverdy, conociera o no al chileno, hubiera o no leído al francés. En textos posteriores, Borges menciona a Huidobro como abanderado de esa concepción del hecho poético, que hace derivar del cubismo, sobre todo a través de las exposiciones de Apollinaire. En Inquisiciones, libro de 1925, hay varias referencias a Huidobro en relación con Apollinaire y Reverdy: artículos sobre González Lanuza, sobre Cansinos-Asséns, sobre el incidente Asséns-Gómez de la Serna. Y hasta llega a insinuar que el ultraísmo era seguidor de la poética huidobriana, insinuación que se hace más explícita a medida que pasan los años y Borges se aleja del ultra. Recojo una de las más cercanas a nosotros. Está en la entrevista de Georges Charbonnier y dice así:

Creo que lo mejor sería ignorar totalmente el ultraísmo. Se trata de un movimiento literario que tuvo su origen en España: se quería imitar a poetas, qué diré yo, del género de Pierre Reverdy. Se quería imitar a Apollinaire, al chileno Huidobro. Una teoría que hoy en- 
cuentro totalmente falsa, que quería reducir la poesía a la metáfora y creía en la posibilidad de hacer nuevas metáforas ${ }^{3}$.

Sabida es la evolución poética de Borges: de ser un «novelero de metáforas», a la búsqueda de un verso que no lo contradiga, que le dé una «certeza espiritual», son sus palabras. $Y$ esto ya antes de 1926, fecha de la aparición del Indice. En cuanto a Hidalgo, sabemos que estaba relacionado con la editorial El Inca, donde había publicado su libro de «poemas inventados» bajo el título de Simplismo (1925) y que en momentos en que elaboraba el Indice toda su fe poética estaba puesta en el creacionismo. La parte del prólogo que le corresponde no dice mucho sobre poesía, ocupado como estaba en la política del continente. Sólo en la última página, después de confesar que «su evidente anticipación en la obra» se encuentra en el «inmenso poeta peruano José María Eguren», afirma: «Tras de eso no hubo nada importante hasta que apareció Huidobro. Huidobro, en España, derroca el rubendarismo», continúa, y concluye que la acción de Huidobro se propaga «a través de los ultraístas argentinos, puesto que el ultraísmo es hechura suya». También Borges insiste en que la nueva actitud poética tiene por objeto derrocar el rubendarismo decadente, sustituirlo, superarlo. Cree que ese avance se logrará poniendo el acento en temas de inspiración autóctona y nuevos medios de expresión, cuya eficacia hace radicar en la imagen, «nuestro universal santo y seña», dice. La imagen no sujeta a la comparación y la prueba, la imagen que hoy llamamos «libre» por oposición a la "atada», según la distinción de Richards, es para ultraístas y creacionistas el signo sine qua non de la nueva poesía. Es la misma imagen que ya había propuesto Baudelaire como «correspondencia» (y no como similitud) y que ensalzaba Reverdy actualizando la discordia concor del doctor Johnson. E1 prólogo de Huidobro es una confirmación de esta doctrina, cuyo fin es doble: A) negar la materialidad de lo poético rechazando todo hecho acontecido que lo predetermine y todo objeto ready made, en especial los que resultaban de la industria, la técnica, el maquinismo, que a la sazón encumbraba el futurismo, y B) crear en el acto poético un hecho nuevo, una relación nueva, cuya existencia sólo fuera posible en el lenguaje (en la mente, dice Huidobro), o sea, un espacio poético que reemplace al espacio natural sólo aludido por la poesía del pasado. El Indice es una confirmación de la práctica creacionista. Y en esto está el papel esencial de Huidobro.

\section{University of Pittsburgh.}

\section{Alfredo A. Roggiano}

\footnotetext{
${ }^{3}$ G. Charbonnier, El escritor y su obra... (México: Siglo XXI, 1967), pp. 14-15.
} 
